\title{
Phonological Activation of Category Coordinates During Speech Planning Is Observable in Children but Not in Adults: Evidence for Cascaded Processing
}

\author{
Jörg D. Jescheniak \\ University of Leipzig
}

\author{
Anja Hahne and Stefanie Hoffmann \\ Max Planck Institute of Cognitive and Brain Sciences
}

\author{
Valentin Wagner \\ University of Leipzig
}

\begin{abstract}
There is a long-standing debate in the area of speech production on the question of whether only words selected for articulation are phonologically activated (as maintained by serial-discrete models) or whether this is also true for their semantic competitors (as maintained by forward-cascading and interactive models). Past research has addressed this issue by testing whether retrieval of a target word (e.g., cat) affects-or is affected by-the processing of a word that is phonologically related to a semantic category coordinate of the target (e.g., doll, related to $d o g$ ) and has consistently failed to obtain such mediated effects in adult speakers. The authors present a series of experiments demonstrating that mediated effects are present in children (around age 7) and diminish with increasing age. This observation provides further evidence for cascaded models of lexical retrieval.
\end{abstract}

Keywords: speech production, lexical access, cascaded processing, development

Speakers are very efficient at converting thought into language, and much research in the past decades has explored the cognitive representations and processes underlying this unique ability. This research has led to models of lexical retrieval converging on the assumption that, during an early phase in speech planning, the to-be-verbalized target concept and a number of semantically related concepts are activated. These activated concepts are assumed to subsequently activate their corresponding abstract lexical representations coding syntactic (and possibly lexical-semantic) information, so-called lemma representations (see Levelt, Roelofs, \& Meyer, 1999; Vigliocco, Vinson, Martin, \& Garrett, 1999). However, there is less agreement on the question of whether all activated lemmas also activate their corresponding phonological representations. Some researchers have maintained that conceptual and lemma-level processing strictly precedes phonological pro-

Jörg D. Jescheniak and Valentin Wagner, Department of Psychology, University of Leipzig, Leipzig, Germany; Anja Hahne and Stefanie Hoffmann, Max Planck Institute of Cognitive and Brain Sciences, Leipzig, Germany.

This research was supported by Deutsche Forschungsgemeinschaft Grants Je229/2-3 and Je229/8-1 and a Heisenberg Fellowship from the German Science Foundation awarded to Jörg D. Jescheniak. We are greatly indebted to the children and teachers from the elementary school Am Holländer in Döbeln, Germany for their enthusiastic participation and support. Ansgar Hantsch and Frank Oppermann helped in programming the experiments. We wish to thank Reinhold Kliegl and Herbert Schriefers for helpful comments on earlier versions of this article.

Correspondence concerning this article should be addressed to Jörg D. Jescheniak, University of Leipzig, Department of Psychology, Seeburgstrasse 14-20, D-04103, Leipzig, Germany. E-mail: jdj@uni-leipzig.de cessing and that phonological codes are only activated for the words actually selected for articulation (serial-discrete models, e.g., Levelt, et al., 1991, 1999). Other researchers, by contrast, have assumed that the activation of lemma representations and the activation of phonological representations are more continuous processes, in that phonological activation can begin before semantic-syntactic processing has terminated with the selection of one candidate lemma (sometimes also referred to as lexical node; forward-cascading models, e.g., Caramazza, 1997; Morsella \& Miozzo, 2002; Peterson \& Savoy, 1998) and may even, via feedback, exert some influence on this selection process at the lemma level (interactive models; e.g., Dell, 1986; Dell et al., 1997; Dell \& O’Seaghdha, 1991, 1992; Harley, 1993).

Past chronometric research has addressed this issue by testing whether retrieval of a picture name (e.g., cat) affects or, depending on the particular experimental task used, is affected by the processing of a word that is phonologically related to a semantic category coordinate to the picture name (e.g., doll, phonologically related to $d o g$ ). Such mediated semantic-phonological priming effects are considered as indexing phonological activation of lexical competitors and thus constitute a crucial test case that allows one to distinguish between serial-discrete models that restrict phonological activation to the target word from nondiscrete models that allow for the activation of multiple phonological codes (e.g., Dell \& O’Seaghdha, 1991, 1992; Jescheniak, Hahne, \& Schriefers, 2003; Jescheniak \& Schriefers, 1998; Levelt et al., 1991, 1999; O'Seaghdha \& Marin, 1997; Peterson \& Savoy, 1998). Thus far, corresponding behavioral and electrophysiological studies with healthy adult speakers have failed to detect mediated priming effects for semantic category coordinates, in line with the prediction of serial-discrete models (Jescheniak et al., 
2003; Levelt et al., 1991; Peterson \& Savoy, 1998). There is one clear exception, though, as mediated priming effects have been repeatedly demonstrated for near-synonyms (e.g., sofa-couch; Peterson \& Savoy, 1998; Jescheniak \& Schriefers, 1998). However, the conclusiveness of this evidence has been questioned. Levelt et al. (1999) argued that synonyms, unlike category coordinates, are adequate lexical alternatives in the context of the communicative situation and thus might be erroneously selected in addition to the target, leading to the simultaneous activation of multiple phonological forms. Such activation of multiple phonological forms following multiple lemma selection is compatible with a weak version of a discrete-serial model.

However, there is a growing body of evidence (beyond the just mentioned finding for synonyms) in support of nondiscrete processing models. Much of this evidence comes from situations in which lexical retrieval has derailed, leading to overt error in healthy and brain damaged speakers. Word substitution errorsfor example, if a speaker produces sword for arrow (Garrett, 1988) - are particularly important. A large proportion of such substitution errors are semantically conditioned, and these errors have been claimed to index problems in retrieving lemma representations, with phonology playing no important role. In a seminal study, however, Dell and Reich (1981) demonstrated that what looks like pure semantic error is in fact phonologically infiltrated. That is, the words involved in semantic word substitutions tend to be phonologically more similar than would be expected by chance if the process giving rise to them was completely blind with respect to phonology. This and related observations led to the suggestion that information leaks between the two lexical processing levels, such that activation cascades down from the lemma level to the phonological level and, in turn, is fed back to the lemma level. In the past years, further support for this view has accumulated from the study of experimentally induced errors in healthy speakers (e.g., Ferreira \& Griffin, 2003; Martin, Weisberg, \& Saffran, 1989) and in patients with aphasia (e.g., Dell, Schwartz, Martin, Saffran, \& Gagnon, 1997; Martin, Gagnon, Schwartz, Dell, \& Saffran, 1996; but see Garrett, 1992, and Levelt, 1992, for different accounts of these data). However, it has also been argued that prime evidence for a processing model of normal speech should preferentially come from error-free speech, not cases in which the production process in some way has derailed (see Levelt et al., 1991).

When we reconsider all these findings, it appears that evidence in support of cascaded processing is often obtained under circumstances in which lexical retrieval, for some reason, is particularly difficult. Situations in which temporal or structural impairments in healthy speakers and speakers with brain damage lead to overt error make a first case. Retrieval difficulties can also be assumed to hold when the lexical competition is particularly strong, as in the presence of near-synonymous competitors. These two cases have been explored in past research. In addition, lexical retrieval might be particularly demanding if the lexical retrieval system has not yet gained maximum efficiency, for example, in children. In fact, previous research has consistently shown that children perform substantially more slowly than do adults in lexical tasks, including picture naming (see Berman, Friedman, Hamberger, \& Snodgrass, 1989; Clark \& Johnson, 1994; Denckla \& Rudel, 1974; Guilford \& Nawojczyk, 1988). In this context it is im- portant to note that, on theoretical grounds, mediated priming effects indicative of cascaded processing must be assumed to be small and, hence, are not easily observed under normal circumstances (Dell \& O’Seaghdha, 1991, 1992; Harley, 1993; O'Seaghdha \& Marin, 1997). In the regular case, a to-beverbalized concept activates a competing lemma (e.g., of a category coordinate) to a lesser extent than its own lemma, and this competing lemma will also transmit only a part of its activation to the word form it is associated with. If lexical retrieval operates at high speed, the activation of the competitor's weakly coactivated phonological form might thus not be detected. However, the situation might be quite different if lexical retrieval is slowed down as is the case in children. That is, one could speculate that the lexical retrieval process in this population is stretched out in time such that all effects are amplified and even a mediated effect might become visible. In particular, a demonstration of a mediated effect for category coordinates would be theoretically important, as it has been thus far considered a critical test of serial-discrete versus cascaded processing by advocates of both model types. Moreover, the interpretation of such an effect-if present-is not affected by arguments raised against the interpretations of the findings from near synonyms and from speech-error analyses.

Surprisingly, the developmental approach has not been taken thus far; in fact, developmental online studies of lexical retrieval in speaking with young children are relatively rare (e.g., Ehri, 1976; Jerger, Martin, \& Damian, 2002; Johnson, 1992; for a review, see Johnson, Paivio, \& Clark, 1996). Still, the considerations just sketched suggest that exploring such developmental aspects could have a great potential for further restricting the set of adequate models of adult lexical processing.

The aim of our study was thus to investigate online lexical retrieval in children and adults. It tested second graders, fourth graders, and young adults using the picture-word interference task that has become a prominent tool for studying adult lexical processing (e.g., Cutting \& Ferreira, 1999; Damian \& Martin, 1999; Jescheniak \& Schriefers, 1998; Jescheniak, Schriefers, \& Hantsch, 2001; Schriefers, Meyer, \& Levelt, 1990; Starreveld \& La Heij, 1995). Participants named pictures of objects while ignoring auditory distractor words. Experiment 1, performed with speakers of different age groups, investigated the effect from distractors phonologically related to a semantic category coordinate (e.g., doll, related to dog, if cat is the target). As in previous studies, this effect was taken as the crucial test case for cascaded lexical processing. The question was whether such an effect, which has as yet not been seen in adult speakers, would be visible in children whose lexical retrieval procedure has not yet gained maximum efficiency. If so, we expected it to manifest itself as interference from these mediated semanticphonological distractors (cf. Jescheniak \& Schriefers, 1998; Jescheniak, Hantsch, \& Schriefers, 2005). Experiment 1 also included phonological distractors, for two reasons. First, as phonological facilitation effects are very robust, the results from these distractors would demonstrate the general sensitivity of the experiment for the case that no mediated effect is obtained in any of the age groups. Second, the results from these distractors would allow us to evaluate whether distractor 
effects are generally amplified in children as compared with adults. ${ }^{1}$

\section{Experiment 1}

Experiment 1 was performed with three different age groups (second graders, fourth graders, and young adults) and tested for the phonological activation of semantic category coordinates (i.e., mediated semantic-phonological interference) and for the phonological activation of the target word (i.e., phonological facilitation). We predicted phonological facilitation effects for all age groups, with effects being larger for children than adults. The crucial question was whether mediated semantic-phonological interference would be obtained for any of these groups.

\section{Method}

\section{Participants}

Thirty-two second graders (ages ranging from 7 years 3 months to 8 years 6 months, $M=7$ years 10 months, $S D=0$ years 4 months) were tested in Experiment 1A, 32 fourth graders (ages ranging from 9 years 4 months to 10 years 8 months, $M=9$ years 11 months, $S D=0$ years 5 months) were tested in Experiment 1B, and 36 undergraduate students from the University of Leipzig (ages ranging from 19 years 3 months to 30 years 2 months, $M=23$ years 7 months, $S D=2$ years 6 months) were tested in Experiment $1 \mathrm{C}$. In this and the following experiments, participants had normal or corrected-to-normal vision and no known hearing impairment. Adults were paid the equivalent of $\$ 7.50$ for their participation, and children received toys and other small gifts at their own choice.

\section{Materials}

Line drawings of 16 objects with unambiguous names were used as experimental pictures. For each picture, two distractors were selected: A first distractor minimally shared the initial consonant-vowel segments with the name of a semantic category coordinate but was phonologically unrelated to the picture name and semantically unrelated to both the picture name and the category coordinate (e.g., distractor Honig [honey], which is related to hose [trousers], if the object name was Mantel [coat], mediated semantic-phonological condition). A second distractor minimally shared the initial consonant-vowel segments with the picture name, but was semantically unrelated to it (e.g., Maske [mask], phonological condition; see Appendix A for a complete list). Unrelated control conditions, against which the effects from the two related distractors could be evaluated, were created by reassigning these distractors to the pictures. Another 6 objects with appropriate distractors were selected to be used in the construction of practice and warm-up trials. We only considered picture names and distractor words that we assumed to be familiar to second graders; this included the names of the mediating semantic category coordinates not appearing in the experiment. The final selection of these words was validated by informal ratings from 10 teachers recruited from the same school as the children participating in Experiment 1.

Pictures were prepared to fill a square of approximately $50 \times 50 \mathrm{~mm}$. Auditory distractor words were spoken by a female native speaker of German. Mediated semantic-phonologically related distractors varied in duration from $448 \mathrm{~ms}$ to $815 \mathrm{~ms}$ with an average of $664 \mathrm{~ms}(S D=98 \mathrm{~ms})$ and phonologically related distractors from $513 \mathrm{~ms}$ to $788 \mathrm{~ms}$ with an average of $690 \mathrm{~ms}(S D=85 \mathrm{~ms})$. For each picture, we also recorded a sentence to be used when familiarizing participants with the pictures and their names. The sentences took the form "This is the $x$," with $x$ being the picture name. These sentences were spoken by a male native speaker of
German. All auditory materials were digitized at a sampling rate of $22 \mathrm{kHz}$ for presentation during the experiment

\section{Design}

There were two pairs of critical comparisons of distractor conditions: distractors phonologically related to a semantic competitor versus unrelated distractors (mediated effect) and distractors phonologically related to the target versus unrelated distractors (phonological effect). In Experiment $1 \mathrm{C}$, in which we tested adult participants, stimulus onset asynchrony (SOA) was varied in three steps $(0 \mathrm{~ms}, 150 \mathrm{~ms}, 300 \mathrm{~ms})$. SOAs were blocked and their sequence was fully counterbalanced across groups of participants, using a Latin square procedure. Each participant received each target picture exactly once in each SOA and each distractor condition. Within each SOA block, the sequence of distractor conditions was counterbalanced using a sequentially balanced random Latin square procedure; across different lists, each distractor condition appeared equally often at each repetition level of a given item in each SOA block with the transition probability for distractor conditions being sequentially controlled. Moreover, the following general criteria were applied in creating 12 different experimental lists: (a) Semantically or phonologically related pictures or distractors did not follow in adjacent trials, (b) repetitions of a picture were separated by at least eight intervening trials, and (c) no more than three trials from the same condition appeared in succession. The 12 experimental lists were used equally often. In Experiment 1B, in which we tested fourth graders, the same SOAs were used, but an SOA of $0 \mathrm{~ms}$ was always presented as the final experimental block, whereas the sequence of SOA $150 \mathrm{~ms}$ and $300 \mathrm{~ms}$ was counterbalanced. In Experiment 1A, in which we tested second graders, only the latter two SOAs were used. ${ }^{2}$ This change reduced the number of experimental lists to 8 .

\section{Procedure}

Participants were tested individually. They were comfortably seated in a dimly lit room, separated from the experimenter by a partition wall. Visual stimuli were presented on a CRT as black line drawings on a light gray background. Viewing distance was about $60 \mathrm{~cm}$. Auditory distractors were presented with Sennheiser HD 495 headphones (Sennheiser, Wedemark, Germany) at a comfortable listening volume. The presentation of all stimuli and the online collection of the data were controlled by a computer with a Pentium processor (Intel Corporation, Santa Clara, CA). Speech-onset latencies were measured to the closest millisecond with a voice key connected to the computer (Nijmegen Experimental Setup system developed at the Max Planck Institute for Psycholinguistics, Nijmegen, the Netherlands, with a Sennheiser ME40 microphone).

In the experimental trials, target pictures were presented in the center of the CRT for $1 \mathrm{~s}$. Auditory distractors started either simultaneously with picture onset $(\mathrm{SOA}=0 \mathrm{~ms}), 150 \mathrm{~ms}$ later $(\mathrm{SOA}=150 \mathrm{~ms})$, or $300 \mathrm{~ms}$ later $(\mathrm{SOA}=300 \mathrm{~ms})$. Speech onset latencies were measured from picture onset.

\footnotetext{
${ }^{1}$ We deliberately refrained from including semantic distractors (i.e., words denoting a category coordinate to a target) in this experiment to distract the participants' attention from the mediated condition. We reasoned that participants might become quickly aware of the mediated relations (e.g., doll-cat) when being exposed to the underlying semantic relations (e.g., dog-cat).

${ }^{2}$ This decision was based on pilot studies that had revealed that an SOA of $0 \mathrm{~ms}$ was particularly difficult for the children. At this SOA, distractors led to a blocking of the naming response on a substantial proportion of trials, even after some training with the task. This was particularly true if an SOA of $0 \mathrm{~ms}$ was presented in the first experimental block.
} 
Adult participants tested in Experiment 1C first received written instructions, which emphasized the speed and accuracy of their responses. They were then familiarized with the pictures and their names. Participants saw each picture on the CRT and listened to the spoken sentence providing its name. The picture remained in view until participants pressed a button and the next picture appeared. In a next step, participants were familiarized with the speeded picture-naming task. The pictures were presented one by one, and the participants named them as quickly as possible. All pictures appeared twice during this phase. The experimenter monitored whether participants used the appropriate names and provided the correct names if necessary. In a final step, participants were familiarized with picture naming in the presence of auditory distractors. There was a practice block with 12 trials, presented with the same SOA that would be used in a participant's initial experimental block. Then the main experiment started, consisting of three SOA blocks and short breaks in between. Each block started with 6 warm-up trials.

For children, tested in Experiments 1A and 1B, the written instructions were replaced with oral instructions, and the amount of training was increased. In the second training phase, including distractors, they received up to four practice blocks (in which also experimental pictures, but no experimental distractors, were used). Practice was discontinued if the individual child's performance approached an acceptable level and did not further improve with respect to the speed and accuracy of responses, according to the experimenter's (Stefanie Hoffmann's) impression.

\section{Results and Discussion}

Observations were coded as erroneous and discarded from the reaction time analyses whenever any of the following conditions held: (a) A picture had been named with other than the expected name, (b) a nonspeech sound preceded the target utterance, triggering the voice key, (c) a dysfluency occurred or an utterance was repaired, or (d) a speech onset latency exceeded 2.5 s. Observations deviating from a participant's and an item's mean by more than $3 S D$ s were considered as outliers and also discarded from the reaction time analyses, as were malfunctions of the voice key. For these latter two cases, however, no errors were coded. According to these criteria, 781 observations $(19.1 \%)$ were discarded in Experiment $1 \mathrm{~A},{ }^{3} 642$ observations (10.5\%) in Experiment 1B, and 280 observations (4.1\%) in Experiment 1C. For each age group, averaged reaction times and error rates were submitted to analyses of variance (ANOVAs), separately for the mediated distractor conditions and the phonological distractor conditions. Statistical analyses involved the fixed variables relatedness (related vs. unrelated) and SOA (0 ms vs. $150 \mathrm{~ms}$ vs. $300 \mathrm{~ms}$, or $150 \mathrm{~ms}$ vs. 300 $\mathrm{ms}$, in Experiment 1A). These analyses for the individual age groups are preceded by joint analyses on all age groups tested in Experiments $1 \mathrm{~A}$ to $1 \mathrm{C}$, restricted to those SOAs received by all participants (i.e., SOAs of 150 and $300 \mathrm{~ms}$ ). For all analyses reported here, the significance level was set at .05 . Probability values are provided only for those cases in which an effect approached but did not reach this criterion.

Table 1 displays mean reaction times and error rates per SOA and distractor type for Experiment 1. Figure 1 displays the reaction time differences between related and unrelated conditions for mediated and phonological conditions separately for each age group and each SOA.

\section{Joint Analysis of Experiments 1A to 1C}

Effects from phonological distractors. These analyses revealed a significant effect of age, $F_{1}(2,97)=104.16, M S E=109,063.15 ; F_{2}(2,30)=$
$347.89, M S E=15,189.52$, for naming latencies, and $F_{1}(2,97)=45.77$, $M S E=3.73 ; F_{2}(2,30)=30.91, M S E=10.03$, for error rates, reflecting the fact that naming latencies and error rates decreased with age. Responses were faster and more accurate in the related condition, yielding significant relatedness effects, $F_{1}(1,97)=206.72, M S E=11,040.91 ; F_{2}(1,15)=$ 66.94, $M S E=16,418.56$, for naming latencies, and $F_{1}(1,97)=19.06$, $M S E=2.06 ; F_{2}(1,15)=7.01, M S E=11.05$, for error rates. Age interacted with relatedness in the analysis of naming latencies, $F_{1}(2,97)=$ $39.77, M S E=11,040.91 ; F_{2}(2,30)=38.29, M S E=4,994.83$, showing that the younger age groups exhibited larger facilitation effects. There was a main effect of SOA, reflecting longer naming latencies and more errors at an SOA of $150 \mathrm{~ms}, F_{1}(1,97)=78.24, M S E=16,362.09 ; F_{2}(1,15)=$ 69.51, $M S E=9,907.90$, for naming latencies, and $F_{1}(1,97)=18.19$, $M S E=1.24 ; F_{2}(1,15)=15.65, M S E=2.82$, for error rates. SOA interacted with relatedness in the analysis of naming latencies, reflecting larger facilitation effects at an SOA of $150 \mathrm{~ms}, F_{1}(1,97)=26.45, M S E=$ $7,415.73 ; F_{2}(1,15)=21.77, M S E=4,647.16$. Finally, there was an interaction of age and SOA, reflecting the fact that the decrease in latencies and error rates from an SOA of $150 \mathrm{~ms}$ to an SOA of $300 \mathrm{~ms}$ was much stronger for children than for adults, $F_{1}(2,97)=18.56, M S E=16,362.09$ $F_{2}(2,30)=30.30, M S E=5,699.55$, for naming latencies, and $F_{1}(2,97)=$ $3.72, M S E=1.24 ; F_{2}(2,30)=3.07, p=.06, M S E=2.73$, for error rates.

Effects from mediated semantic-phonological distractors. Again, there was a significant effect of age, $F_{1}(2,97)=98.40$, $M S E=160,625.63 ; F_{2}(2,30)=318.01, M S E=22,594.01$, for naming latencies, and $F_{1}(2,97)=34.89, M S E=7.54 ; F_{2}(2,30)=$ $66.98, M S E=7.13$, for error rates, reflecting the fact that naming latencies and error rates decreased with age. Responses were slower in the related condition than in the unrelated condition, although the effect was only significant in the participant analysis and approaching significance in the item analysis, $F_{1}(1,97)=$ 9.28, $M S E=6,634.07 ; F_{2}(1,15)=3.85, p=.07, M S E=$ $8,267.97$. Most important, the interaction of age and relatedness was significant in the analysis of naming latencies, $F_{1}(2,97)=$ 4.30, $M S E=6,634.07 ; F_{2}(2,30)=3.97, M S E=4,485.02$, reflecting the fact that mediated distractors led to interference in the youngest age group but not in adults. There was also a significant effect of SOA, $F_{1}(1,97)=101.40, M S E=19,424.04$; $F_{2}(1,15)=280.55, M S E=3,761.91$, for naming latencies, and $F_{1}(1,97)=3.49, p=.07, M S E=2.49 ; F_{2}(1,15)=10.29$, $M S E=1.64$, for error rates, reflecting slower responses and more errors at an SOA of $150 \mathrm{~ms}$. SOA also interacted with age in the analysis of naming latencies, reflecting the fact that the decrease from an SOA of $150 \mathrm{~ms}$ to an SOA of $300 \mathrm{~ms}$ was much stronger for children than for adults, $F_{1}(2,97)=19.25, M S E=19,424.04$;

\footnotetext{
${ }^{3}$ Overall error rates for this group amounted to $18.9 \%$. They were distributed as follows across coded categories: (a) wrong picture names in $2.3 \%$ of cases, (b) nonspeech sound triggering the voice key in $2.3 \%$ of cases, (c) disfluencies in $3.1 \%$ of cases, and (d) time-outs (reaction time $>$ $2.5 \mathrm{~s}$ ) in $11.3 \%$ of cases. That is, most of the errors resulted from trials in which participants did not respond in a timely way or did not respond at all (mediated related, $12.9 \%$; mediated unrelated, $11.8 \%$; phonologically related, $8.0 \%$; phonologically unrelated, $12.4 \%$ ). This is consistent with our finding from the pilot studies that blocking of responses was a frequent event in this age group, in particular when target and distractor were presented in close succession or simultaneously. Nevertheless, it should be noted that there was substantial variability between participants, some performing with adult accuracy (less than 5\% errors) and others exhibiting high error rates (about 40\%). Closer inspection of the data, however, did not reveal a natural cutoff criterion for replacing individual participants.
} 
Table 1

Mean Naming Latencies (in Milliseconds) and Errors (in Percentages) From Experiment 1

\begin{tabular}{|c|c|c|c|c|c|c|}
\hline \multirow[b]{2}{*}{ Distractor type } & \multicolumn{3}{|c|}{ Phonological conditions } & \multicolumn{3}{|c|}{$\begin{array}{l}\text { Mediated semantic-phonological } \\
\text { conditions }\end{array}$} \\
\hline & SOA $0 \mathrm{~ms}$ & SOA $150 \mathrm{~ms}$ & SOA $300 \mathrm{~ms}$ & SOA $0 \mathrm{~ms}$ & SOA $150 \mathrm{~ms}$ & SOA $300 \mathrm{~ms}$ \\
\hline \multicolumn{7}{|c|}{ 2nd graders } \\
\hline \multicolumn{7}{|l|}{ Related } \\
\hline M & - & 1,034 & 894 & - & 1,351 & 1,135 \\
\hline$S E$ & - & 52 & 45 & - & 59 & 67 \\
\hline$\%$ error & - & 16.8 & 11.1 & - & 21.1 & 22.3 \\
\hline$S E$ & - & 1.6 & 1.6 & - & 2.6 & 2.8 \\
\hline \multicolumn{7}{|l|}{ Unrelated } \\
\hline M & - & 1,365 & 1,100 & - & 1,303 & 1,068 \\
\hline$S E$ & - & 53 & 58 & - & 53 & 62 \\
\hline$\%$ error & - & 22.3 & 18.2 & - & 21.9 & 18.0 \\
\hline$S E$ & - & 2.8 & 2.8 & - & 2.6 & 2.5 \\
\hline \multicolumn{7}{|l|}{ Difference } \\
\hline$M$ & & $-330 * * * / * * *$ & $-206 * * * * * * *$ & & 48 & $66^{* / \dagger} \dagger$ \\
\hline$S E$ & & 31 & 37 & & 29 & 31 \\
\hline$\%$ error & & $-5.5 t^{\prime n s}$ & $-7.0 * * / *$ & & -0.8 & $4.3 * * / *$ \\
\hline$S E$ & & 2.8 & 2.5 & & 2.1 & 1.5 \\
\hline
\end{tabular}

4th graders

\begin{tabular}{|c|c|c|c|c|c|c|}
\hline \multicolumn{7}{|l|}{ Related } \\
\hline$M$ & 873 & 767 & 687 & 1,006 & 951 & 773 \\
\hline$S E$ & 23 & 22 & 15 & 32 & 39 & 29 \\
\hline$\%$ error & 9.2 & 7.2 & 4.7 & 12.5 & 13.5 & 8.6 \\
\hline$S E$ & 1.4 & 1.5 & 0.9 & 1.5 & 2.2 & 1.7 \\
\hline \multicolumn{7}{|l|}{ Unrelated } \\
\hline$M$ & 1,042 & 955 & 789 & 989 & 928 & 762 \\
\hline$S E$ & 32 & 39 & 26 & 31 & 33 & 25 \\
\hline$\%$ error & 12.9 & 12.7 & 8.0 & 10.4 & 11.5 & 8.6 \\
\hline$S E$ & 1.7 & 2.0 & 1.1 & 1.8 & 2.0 & 1.4 \\
\hline \multicolumn{7}{|l|}{ Difference } \\
\hline$M$ & $-169 * * * / * * *$ & $-188 * * * / * * *$ & $-102 * * * / * * *$ & 17 & 23 & 12 \\
\hline$S E$ & 24 & 30 & 18 & 20 & 19 & 18 \\
\hline$\%$ error & $-3.7 \dagger^{\prime} \dagger$ & $-5.5^{*} n s$ & $-3.3 * / \dagger$ & 2.1 & 2.0 & 0.0 \\
\hline$S E$ & 2.1 & 2.6 & 1.4 & 1.8 & 1.8 & 1.3 \\
\hline \multicolumn{7}{|c|}{ Adults } \\
\hline \multicolumn{7}{|l|}{ Related } \\
\hline$M$ & 511 & 492 & 506 & 575 & 545 & 518 \\
\hline$S E$ & 9 & 6 & 5 & 10 & 7 & 5 \\
\hline$\%$ error & 3.8 & 2.6 & 2.6 & 5.6 & 3.8 & 2.8 \\
\hline$S E$ & 0.9 & 0.8 & 0.7 & 0.9 & 0.9 & 0.8 \\
\hline \multicolumn{7}{|l|}{ Unrelated } \\
\hline$M$ & 597 & 561 & 518 & 572 & 542 & 521 \\
\hline$S E$ & 9 & 8 & 6 & 9 & 7 & 6 \\
\hline$\%$ error & 4.2 & 4.2 & 3.3 & 4.3 & 3.3 & 3.8 \\
\hline$S E$ & 0.7 & 0.6 & 0.6 & 0.9 & 0.8 & 0.8 \\
\hline \multicolumn{7}{|l|}{ Difference } \\
\hline$M$ & $-86 * * * * * * *$ & $-69 * * * * * * *$ & $-13 * * * * * * *$ & 3 & 3 & -3 \\
\hline$S E$ & 6 & 5 & 3 & 5 & 3 & 3 \\
\hline$\%$ error & -0.3 & -1.6 & -0.7 & 1.2 & 0.5 & -1.0 \\
\hline$S E$ & 1.1 & 1.0 & 0.8 & 1.1 & 1.0 & 0.8 \\
\hline
\end{tabular}

Note. The dashes indicate that SOA $0 \mathrm{~ms}$ was not tested in this age group. Positive difference scores reflect interference, and negative difference scores reflect facilitation. Significance of these scores is indicated by the superscripts. The first superscript indicates results from the $t$ tests by participant. The second superscript indicates results from the $t$ tests by item. SOA $=$ stimulus onset asynchrony.

$\dagger p<.10 . \quad * p<.05$. *** $p<.01$. *** $p<.001$. 


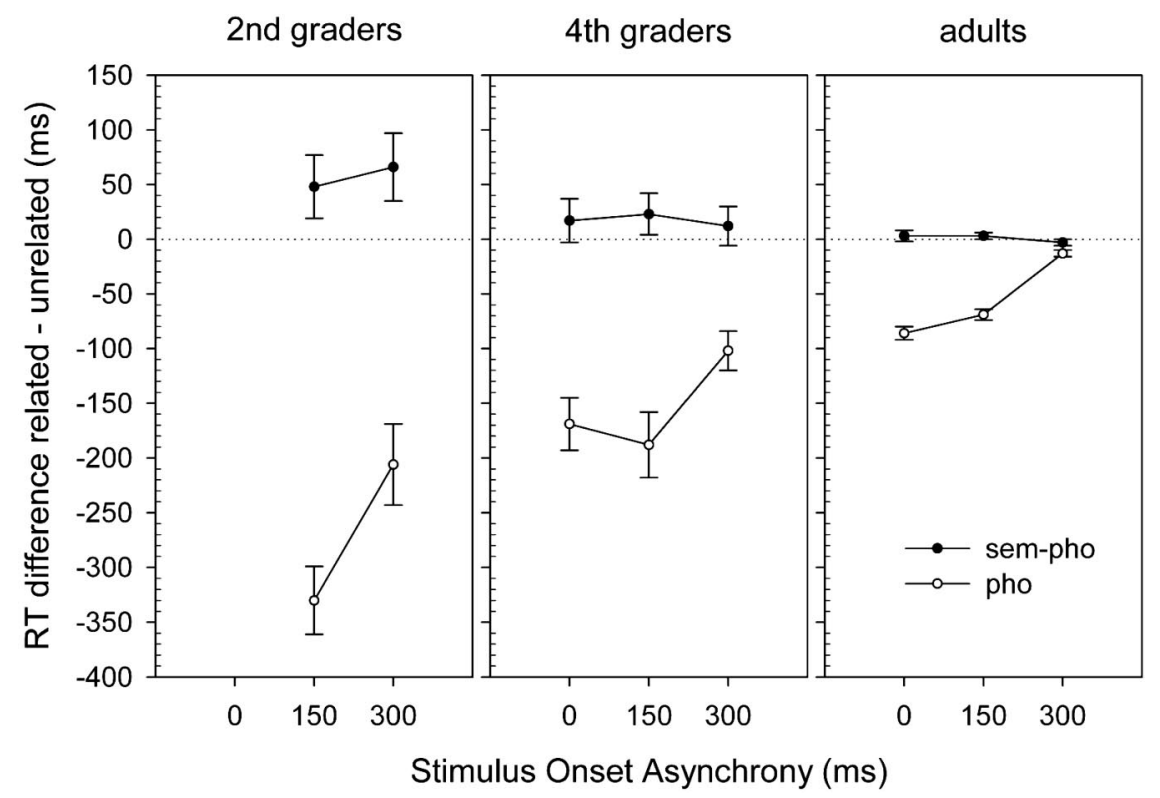

Figure 1. Mean reaction time (RT) differences (related-unrelated) and standard errors (in milliseconds) for the mediated and phonological conditions from Experiment 1. Positive scores reflect interference; negative scores reflect facilitation sem-pho $=$ mediated semantic-phonological conditions; pho $=$ phonological conditions .

$F_{2}(2,30)=95.13, M S E=2,266.94$. Finally, there was an interaction of age, SOA, and relatedness in the analysis of error rates, reflecting the fact that in second graders interference in the related condition was seen at an SOA of $300 \mathrm{~ms}$ but for fourth graders such a trend was visible at an SOA of $150 \mathrm{~ms}, F_{1}(2,97)=3.42$, $M S E=0.95 ; F_{2}(2,30)=2.93, p=.07, M S E=2.24$.

Next, analyses for the individual age groups are reported. These analyses included all SOAs that were tested with a particular group.

\section{Experiment 1A: Second Graders}

Effects from phonological distractors. Phonologically related distractors facilitated naming responses, $F_{1}(1,31)=109.45$, $M S E=21,035.42 ; F_{2}(1,15)=62.80, M S E=17,199.03$, for naming latencies, and $F_{1}(1,31)=8.41, M S E=3.81 ; F_{2}(1,15)=$ $5.58, M S E=11.47$, for error rates. Naming latencies and error rates decreased with longer SOAs, $F_{1}(1,31)=44.20, M S E=$ $29,722.71 ; F_{2}(1,15)=52.74, M S E=14,883.87$, for naming latencies, and $F_{1}(1,31)=7.72, M S E=2.53 ; F_{2}(1,15)=7.92$, $M S E=4.93$, for error rates. Relatedness interacted with SOA in the analysis of naming latencies, $F_{1}(1,31)=7.42, M S E=$ $\left.16,614.05 ; F_{2}(1,15)=9.28, M S E=7,023.90\right)$. The $t$ tests we performed revealed that faster responses with related distractors were obtained at each SOA, but the effect was smaller at an SOA of $300 \mathrm{~ms}$.

Effects from mediated semantic-phonological distractors. Mediated distractors led to longer naming latencies than unrelated distractors, $F_{1}(1,31)=6.42, M S E=16,278.27 ; F_{2}(1,15)=4.61$, $M S E=13,944.27$. Descriptively, error rates pointed into the same direction, with $1.8 \%$ more errors in the related condition. This trend, however, was not reliable, $F_{1}(1,31)=2.12, p=.16$, $M S E=1.19 ; F_{2}(1,15)=3.05, p=.10, M S E=1.66$. Naming latencies decreased with longer SOAs, $F_{1}(1,31)=41.92, M S E=$ $38,917.08 ; F_{2}(1,15)=261.64, M S E=3,971.56$. There was no interaction of relatedness and SOA in the analysis of naming latencies $\left(F_{1}\right.$ and $\left.F_{2}<1\right)$, but there was a trend in the analysis of error rates, $F_{1}(1,31)=3.54, p=.07, M S E=1.49 ; F_{2}(1,15)=$ $3.41, p=.09, M S E=3.10$, reflecting the fact that more errors in the related condition were only observed at an SOA of $300 \mathrm{~ms}$.

\section{Experiment 1B: Fourth Graders}

Effects from phonological distractors. Phonologically related distractors facilitated naming responses, $F_{1}(1,31)=66.40$, $M S E=16,912.48 ; F_{2}(1,15)=42.18, M S E=14,394.96$, for naming latencies, and $F_{1}(1,31)=8.70, M S E=2.45 ; F_{2}(1,15)=$ $5.44, M S E=7.84$, for error rates. Naming latencies and error rates decreased with longer SOAs, $F_{1}(2,62)=49.14, M S E=$ $15,684.50 ; F_{2}(2,30)=50.52, M S E=8,035.58$, for naming latencies, and $F_{1}(2,62)=7.39, M S E=1.34 ; F_{2}(2,30)=9.34$, $M S E=2.12$, for error rates. Relatedness interacted with SOA in the analysis of naming latencies, $F_{1}(2,62)=5.46, M S E=$ 5,981.96; $F_{2}(2,30)=7.13, M S E=2,464.17$. The $t$ tests we performed revealed that faster responses with related distractors were obtained at each SOA, but the effect was smaller at an SOA of $300 \mathrm{~ms}$.

Effects from mediated semantic-phonological distractors. Descriptively, longer naming latencies and more errors were observed with related distractors, but these effects could not be confirmed statistically, $F_{1}(1,31)=2.71, p=.11, M S E=5,179.57 ; F_{2}(1$, $15)=1.07, p=.32, M S E=3,606.18$, for naming latencies, and $F_{1}(1,31)=1.91, p=.18, M S E=1.20 ; F_{2}(1,15)=1.66, p=.22$, $M S E=2.77$, for error rates. Naming latencies and error rates decreased with longer SOAs, $F_{1}(2,62)=53.97, M S E=$ $16,965.92 ; F_{2}(2,30)=123.86, M S E=3,657.99$, for naming, and 
$F_{1}(2,62)=2.46, p=.09, M S E=2.71 ; F_{2}(2,30)=4.92, M S E=$ 2.71 , for error rates. There was no interaction of relatedness and SOA (all $F \mathrm{~s}<1$, for naming latencies and error rates).

\section{Experiment 1C: Adults}

Effects from phonological distractors. Phonologically related distractors led to faster naming latencies, $F_{1}(1,35)=382.58$, $M S E=438.70 ; F_{2}(1,15)=100.25, M S E=754.69$. Naming latencies decreased with longer SOAs, $F_{1}(2,70)=25.88, M S E=$ $1,241.80 ; F_{2}(2,30)=39.76, M S E=371.66$. Relatedness interacted with SOA in the analysis of naming latencies, $F_{1}(2,70)=$ $71.04, M S E=372.69 ; F_{2}(2,30)=29.92, M S E=393.10$. The $t$ tests we performed revealed that faster responses with related distractors were obtained at each SOA, but the effect was smaller at an SOA of $300 \mathrm{~ms}$.

Effects from mediated semantic-phonological distractors. Naming latencies decreased with longer SOAs, $F_{1}(2,70)=27.44$, $M S E=1,949.00 ; F_{2}(2,30)=56.60, M S E=438.82$. Most important, there was no reliable effect of relatedness, neither in the analysis of naming latencies nor in the analysis of error rates: main effect and interaction with relatedness, all $F_{\mathrm{S}}<1$, except $F_{1}(2$, $70)=1.43, p=.25, M S E=0.43$, for the interaction in the participant analysis of error rates.

As predicted, distractor effects were much larger in children than in adults. This was true for facilitation from phonologically related distractors, which was visible in all age groups. Interference from mediated distractors, by contrast, was seen only in young participants, not in adult participants. Albeit not extraordinary strong, for second graders the effect reached significance in the analysis of naming latencies, and there was an additional trend in the error analysis (with $1.8 \%$ more errors in the related condition). It seems, thus, that part of the effect manifested itself in the latency data and another part in the error data. When evaluating the theoretical significance of this pattern, one should reconsider that this interference effect must be expected to be small on theoretical grounds. A competitor's phonological form will always receive only a fraction of the competitor's lemma activation, and that lemma will - in the regular case — start with a lower activation than the lemma of the target word (see Dell \& O'Seaghdha, 1991, 1992); consequently, a mediated effect of the type investigated has as yet not been observed with adult speakers in the context of conceptually driven lexical retrieval tasks, such as picture naming. In other domains, it could be confirmed statistically only when data were pooled across multiple experiments testing a large number of participants (see O'Seaghdha \& Marin, 1997, for mediated effects in word naming).

With this qualification in mind, the data pattern invites the conclusion that phonological coactivation of category coordinates is strong enough to become visible in young speakers for which the lexical retrieval process is stretched out in time. However, before drawing that conclusion, we need to address an important issue relating to the nature of the experimental task. Although the picture-word interference task that we used in our experiments has become a standard tool for exploring lexical retrieval in speech production, it is a hybrid task in that it involves comprehension (i.e., auditory distractor recognition) as well as production components (i.e., object name retrieval). Jescheniak and Schriefers (1998) argued that valid inferences may only be drawn when taking these two components and their possible interaction into account (see also Starreveld, 2000). For the issue at hand here, this caveat is particularly important as one can only unambiguously attribute the age-related differential behavioral pattern to differences in speech production processes in children and adults if one can show that the different age groups do not differ with respect to (auditory) word recognition. For example, the pattern observed in Experiment 1 could in part or fully be due to the fact that children process auditory words in a qualitatively different way than adults do. Word recognition studies with adults have convincingly shown that upon their hearing the segments /do/, both $d o g$ and doll are activated at a semantic level. However, as soon as the segment /l/ is being processed, the coactivated candidate word dog becomes immediately deactivated (e.g., Marslen-Wilson, 1987; Zwitserlood, 1989). Given that children differ from adults in their ability with respect to inhibitory control (cf. Dempster, 1992), it is reasonable to speculate that such rapid deactivation of inappropriate lexical candidates may not operate in children in the very same way as it does in adults. Such a difference would be critical with respect to the locus of the mediated effect. If, for example, dog would not effectively and quickly be deactivated in the mental lexicon of the child upon hearing the segment $/ 1 /$, the interference effect in the mediated condition (if cat is the target) would not come as a surprise; in fact, it would then reflect not phonological activation of semantic category coordinates but the persisting semantic activation of these words, and for that case interference has been demonstrated in numerous studies (e.g., Damian \& Martin, 1999; Glaser \& Düngelhoff, 1984; Jescheniak et al., 2001; Lupker, 1979; Rosinski, 1977; Schriefers et al., 1990; Starreveld \& La Heij, 1995; Underwood, 1976).

A related point has been made by Jescheniak and Schriefers (1998). In a theoretical analysis of the picture-word interference task, these authors traced the possible locus or loci of mediated effects in detail. They pointed out that under certain assumptionsincluding (a) that the activation of multiple lexical candidates triggered by the distractor percolates from the word form to the lemma level and (b) that the temporal synchronization of activation triggered by the picture and activation triggered by the distractor meets certain constraints - there might be a short phase at an early point in time during which mediated effects could arise but have their source at the lemma level, not the phonological level. Like the caveat mentioned before, this theoretical possibility critically hinges on the assumptions one makes about processing of the auditory distractor word. If the time window during which the mediated distractor activates the lemma of the semantic category coordinate to the target is much longer in children than in adults, mediated effects of the type just sketched might more likely be detected in children than in adults but would not speak to the issue of phonological activation of semantic category coordinates.

Unfortunately, relatively little is known with respect to the question of whether or not lexical activation and deactivation in auditory word recognition operates in a comparable way in children and adults (W. Marslen-Wilson and L. Tyler, personal communication, August 2002). There is a growing consensus that initial word recognition is relatively holistic and that representations become more segmentally based with development (e.g., Jusczyk, 1986, 1992; Walley, 1993). It has also been suggested that this process may even extend into early childhood (Fowler, 1991). Consistent with this view is the observation that first 
graders need more auditory input than adults before correctly identifying a target word in gating studies (e.g., Garlock, Walley, \& Metsala, 2001; Walley, 1988; Walley, Michela, \& Wood, 1995). However, these studies do not speak directly to the issue at stake here, namely, whether rapid deactivation of initially activated lexical candidates occurs in children (i.e., second graders and older) in the same way as in adults. In order to explore whether the interference effect in the mediated condition is in part or fully due to differences in auditory word recognition (because the mediated distractor activated the lemma of a semantic category coordinate for an extended period of time) or due to lexical retrieval in speech planning (because activation cascaded from the conceptual level via the lemma of a semantic category coordinate to its associated word form), we thus conducted Experiment 2.

\section{Experiment 2}

\section{Method}

Experiment 2 used a speeded word-picture matching task. Participants were presented with an auditory word and a picture appearing immediately at the offset of the auditory stimulus. The participants' task was to indicate, as quickly and as accurately as possible, whether the auditory word denotes the picture name or not by pressing one of two buttons. For example, they would hear the word doll immediately followed by a picture of a cat (mediated condition) and, on a different trial, the auditory word would be $d o g$ for the same picture (semantic condition; actually, a different item set was used in this condition, as described later). For adults, we expected an interference effect in the semantic condition $(\operatorname{dog})$ and no specific effect in the mediated condition ( $d o l l$ ). To the extent that children differ from adults in that they cannot quickly inhibit inappropriate lexical (lemma) representations upon processing segmental mismatch (i.e., keeping $d o g$ active when having heard $d o l l)$, we expected them to respond to doll and $d o g$ in a comparable way, exhibiting interference in both conditions.

\section{Participants}

Twenty-four second graders (ages ranging from 7 years 5 months to 8 years 11 months, $M=8$ years 1 month, $S D=0$ years 4 months) were tested in Experiment 2A, and 24 undergraduate students from the University of Leipzig (ages ranging from 20 years 0 months to 27 years 7 months, $M=23$ years 4 months, $S D=2$ years 0 months) were tested in Experiment 2B.

\section{Materials}

The same materials as in Experiment 1 were used for the mediated condition, with the distractor words now figuring as probe words. In order to detract our participants' attention from the mediated condition, we refrained from using the names of the mediating category coordinates in the semantic condition. This decision was based on the consideration that the relation between doll and cat might become more salient and thus possibly subject to strategic behavior after processing of the pair dog-cat. Rather, we selected an additional set of 16 experimental pictures and 6 practice pictures (plus corresponding probe words) for realizing the semantic condition (see Appendix B). In selecting the new set of picture names and semantically related probe words, we followed the same constraints as in Experiment 1. The auditory probe words were spoken by the same female speaker as in Experiment 1 . Semantically related probe words varied in duration from 502 to $845 \mathrm{~ms}$ with an average of $660 \mathrm{~ms}(S D=$ $90 \mathrm{~ms}$ ), and probe words used in the mediated condition (rerecorded, to keep acoustic parameters constant across the word sets used in the different conditions included in the experiment) varied in duration from 510 to 810 ms with an average of $664 \mathrm{~ms}(S D=95 \mathrm{~ms})$. Unrelated control conditions, against which the effects from the two related conditions could be evaluated, were created by reassigning the probe words to the pictures.

Both sets of pictures were also tested in an identity condition (e.g., the word cat followed by a picture of a cat). This condition (and its control) was not of particular interest but was included only to create trials for which a positive response had to be given. These trials were thus not included in the statistical analyses. In all, there were $75 \%$ no trials and $25 \%$ yes trials.

\section{Design}

For each age group, there were two pairs of critical comparisons of conditions: the mediated condition versus its control and the semantic condition versus its control. Each participant received each target picture exactly once in each of four conditions: the mediated condition (or, depending on item set, the semantic condition), its control, the identity condition, and its control. These trials were assigned to two different blocks such that each word appeared once and each picture twice in each block, once in a related and once in a control condition. The presentation sequence of the blocks was counterbalanced across participant groups, and the sequence of conditions for a particular item was controlled using a sequentially balanced Latin square procedure. Moreover, the following general criteria were applied in creating four different experimental lists: (a) Semantically or phonologically related pictures or distractors did not follow in adjacent trials, (b) repetitions of a picture were separated by at least 16 intervening trials, (c) no more than 3 trials from the same condition appeared in succession, and (d) no more than 9 trials requiring the same response appeared in succession. The four experimental lists were used equally often.

\section{Procedure}

Participants were tested individually, using the same equipment as in the previous experiments. Responses were collected with a push button box containing two response buttons, one labeled yes and the other labeled no. Participants received oral (children) or written instructions (adults). Unlike in the previous experiment, participants were not familiarized with the pictures to rule out participants' being able to anticipate no responses when hearing probe words used in the semantic and in the mediated condition (and for which no matching pictures were included in the experiment). After receiving two practice blocks with 24 practice trials each, the main experiment started. It consisted of two blocks with 64 trials each, preceded by 6 warm-up trials. For the children, there were additional breaks halfway within each experimental block. A trial started with the presentation of the auditory probe word. Simultaneously with its offset, the picture was presented in the center of the CRT and remained visible for $1 \mathrm{~s}$. Reaction times were measured from the onset of the picture. At the end of the experiment, participants were asked to provide the name for each of the pictures that they would spontaneously use to label that picture.

\section{Results and Discussion}

Observations were coded as erroneous and discarded from the reaction time analyses whenever the participant (a) had given the wrong push-button response or (b) had failed to respond within $2.5 \mathrm{~s}$. Observations deviating from a participant's and an item's mean by more than $3 S D$ s were considered as outliers and also discarded from the reaction time analyses (but not coded as errors). According to these criteria, 106 observations (6.9\%) were discarded in Experiment 2A and 67 observations (4.4\%) in Experiment $2 \mathrm{~B}$. Averaged reaction times and error rates were submitted 
to $t$ tests, separately for the mediated conditions and the semantic conditions.

Table 2 displays mean reaction times and error rates for the mediated and the semantic conditions and the respective controls for Experiment 2. Figure 2 displays normalized reaction time differences between related and unrelated conditions for mediated and semantic conditions separately for each age group.

\section{Semantic Conditions}

Children took more time to respond than adults, $F_{1}(1,46)=$ 95.90, $M S E=27,065.57 ; F_{2}(1,15)=352.14, M S E=5,232.16$. Responses were slower and less accurate in the semantically related than in the unrelated condition, $F_{1}(1,46)=181.63, M S E=$ $2,471.74 ; F_{2}(1,15)=30.85, M S E=12,245.42$, for reaction times, and $F_{1}(1,46)=74.81, M S E=1.20 ; F_{2}(1,15)=9.86, M S E=$

Table 2

Mean Reaction Times (in Milliseconds) and Errors (in Percentages) From Experiment 2

\begin{tabular}{lcc}
\hline Distractor type & $\begin{array}{c}\text { Semantic } \\
\text { conditions }\end{array}$ & $\begin{array}{c}\text { Mediated semantic- } \\
\text { phonological } \\
\text { conditions }\end{array}$ \\
\hline & 2nd graders & \\
Related & & \\
$M$ & 941 & 819 \\
$S E$ & 33 & 38 \\
$\%$ error & 13.5 & 1.6 \\
$S E$ & 1.9 & 0.7 \\
Unrelated & 765 & 810 \\
$M$ & 29 & 34 \\
$S E$ & 1.6 & 0.8 \\
$\%$ error & 0.7 & 0.6 \\
$S E$ & $176^{* * * * * * *}$ & 9 \\
Difference & 19 & 13 \\
$M$ & $12.0^{* * * * *}$ & 0.8 \\
$S E$ & 1.8 & 0.6 \\
$\%$ error & & \\
$S E$ &
\end{tabular}

Adults

Related

$\begin{array}{ccc}M & 573 & 493 \\ S E & 16 & 17 \\ \% \text { error } & 12.2 & 0.5 \\ S E & 2.1 & 0.4 \\ \text { Unrelated } & & \\ M & 475 & 487 \\ S E & 16 & 16 \\ \% \text { error } & 0.0 & 0.0 \\ S E & 0.0 & 0.0 \\ \text { Difference } & & 6 \\ M & 97 * * * * * & 6 \\ S E & 8 & 0.5 \\ \% \text { error } & 12.2 * * * * * & 0.4 \\ S E & 2.1 & \end{array}$

Note. Positive difference scores reflect interference, and negative difference scores reflect facilitation. Significance of these scores is indicated by the superscripts. The first superscript indicates results from the $t$ tests by participant. The second superscript indicates results from the $t$ tests by item. SOA $=$ stimulus onset asynchrony.

$* p<.05$. ** $p<.01$. **** $p<.001$.
13.71, for error rates. Age interacted with relatedness in the analysis of reaction times, $F_{1}(1,46)=15.01, M S E=2,471.74 ; F_{2}(1$, $15)=8.16, M S E=4,462.20$, showing that the interference effect in the semantically related condition was larger in children than in adults. ${ }^{4}$ Subsequently computed $t$ tests, however, revealed that the interference effect was significant in children as well as in adults.

\section{Mediated Semantic-Phonological Conditions}

Again, there was a significant effect of age in the analysis of reaction times with children performing slower than adults, $F_{1}(1$, 46) $=69.33, M S E=36,504.19 ; F_{2}(1,15)=811.37, M S E=$ $2,054.17$. There was no main effect of relatedness in the analysis of reaction times and only a slight trend toward interference in the related condition in the analysis of error rates, $F_{1}(1,46)=1.09$, $p=.30, M S E=1,269.56 ; F_{2}<1$, for reaction times, and $F_{1}(1$, $46)=3.71, p=.06, M S E=0.07 ; F_{2}(1,15)=1.34, p=.26$, $M S E=0.29$, for error rates. Most important, age did not interact with relatedness $(F \mathrm{~s}<1$, for reaction times and error rates), showing that children did not process the mediated related condition differently from adults.

As predicted, interference was obtained when participants had to give a no response to pictures preceded by a semantically related word. This was true for both children and adults, with the effect being larger in children. More important, there was no reliable relatedness effect for the mediated condition, and that was true for both adults and children. This pattern shows that children did not process the mediated words as semantically related words. Rather, they appear to be capable of rapidly and effectively inhibiting initially activated lexical candidates upon processing mismatching segmental information, in a comparable way to that of adults. The result from Experiment 2 thus rules out the possibility that what we have interpreted as a mediated effect originating at the word-form level could in fact be a lemma-level effect.

Although we now have good evidence that the interference effect obtained for the mediated condition in children in Experiment 1 is most likely due to production rather than comprehension processes and is to be located at the word-form level, one could still argue that-because of the substantial differences in response latencies between children and adults-the SOAs tested in Experiment 1 might be functionally different for the age groups and that this difference is the true source of the differential pattern in the mediated condition. For instance, one could speculate that the distractor could exert its influence for a much longer time in children than in adults-for example, by reverberating activation in the mental lexicon and thereby affecting the state of representations subsequently accessed during speech planning. Experiment 3 was performed to rule out this possibility.

\footnotetext{
${ }^{4}$ The relatively high number of erroneous responses in the semantically related condition did not result from conceptual ambiguity of the pictorial stimuli or incomplete conceptual-lexical knowledge in the children (such that, e.g., a dress could have been categorized as a skirt). In fact, when we asked participants after the experiment to provide the name for each of the pictures used, adults never responded with one of the semantically related probe words and children did so only in 5 (out of 384) cases-once for Koffer (suitcase), once for Kran (crane), and three times for Löwe (lion).
} 


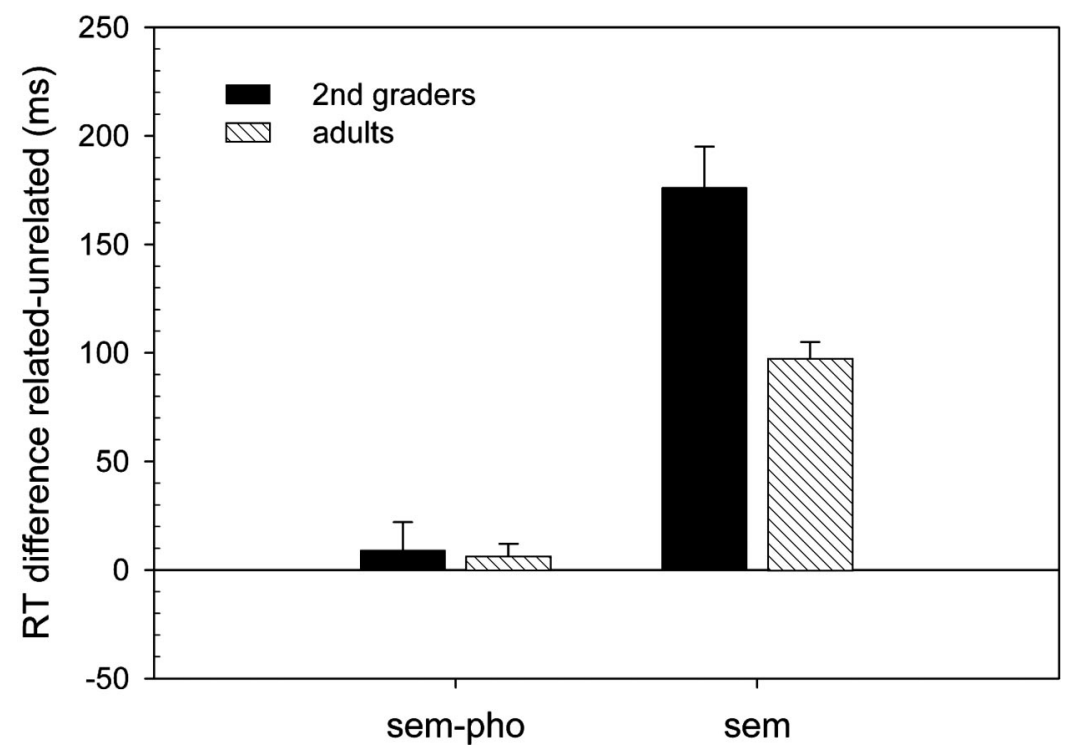

Figure 2. Mean reaction time (RT) differences (related-unrelated) and standard errors (in milliseconds) for the mediated and semantic conditions from Experiment 2. Positive scores reflect interference; negative scores reflect facilitation sem-pho $=$ mediated semantic-phonological conditions; sem $=$ semantic conditions

\section{Experiment 3}

\section{Method}

In Experiment 3, adult speakers were tested with SOAs adjusted in a way that the lag between distractor onset and response onset was now comparable to the respective delay in second graders. If the differential time span available for distractor processing prior to response initiation is the source of the differential behavioral pattern in Experiment 1, we would expect adult participants to yield the same pattern in Experiment 3 as children have shown in Experiment 1A.

\section{Participants}

Forty-eight undergraduate students from the University of Leipzig (ages ranging from 17 years 9 months to 29 years 5 months, $M=22$ years 8 months, $S D=3$ years 1 month) were tested.

\section{Materials}

The materials were the same as in Experiment 1.

\section{Design}

The design was the same as in Experiment 1, except that SOAs were modified as to adjust for the difference in naming speed between second graders and adults. As children had performed about $670 \mathrm{~ms}$ slower than adults (average across unrelated conditions in those SOAs tested in both groups), we moved the SOA window by $600 \mathrm{~ms}(-600 \mathrm{~ms},-450 \mathrm{~ms}$, and $-300 \mathrm{~ms}$, in place of $0 \mathrm{~ms}, 150 \mathrm{~ms}$, and $300 \mathrm{~ms}$ ).

\section{Procedure}

The procedure was the same as in Experiment 1.

\section{Results and Discussion}

The data were treated as in Experiment 1. A total of 251 observations $(2.7 \%)$ were discarded from the reaction time analysis. Table 3 displays mean naming latencies and error rates per SOA and distractor type for Experiment 3.

\section{Effects From Phonological Distractors}

There was a slight trend toward faster responses in the phonologically related condition than in the unrelated condition, but this trend was not reliable, $F_{1}(1,47)=2.34, p=.13, M S E=744.34$; $F_{2}<1$. Naming latencies increased at shorter negative SOAs and there was a corresponding trend for error rates, $F_{1}(2,94)=16.33$, $M S E=1,190.89 ; F_{2}(2,30)=33.75, M S E=194.14$, for naming latencies, and $F_{1}(2,94)=2.44, p=.09, M S E=0.43 ; F_{2}(2,30)=$ $2.79, p=.08, M S E=1.12$, for error rates. There was no interaction of relatedness and $\operatorname{SOA}\left(F_{1}\right.$ and $F_{2}<1$, for naming latencies and error rates.

\section{Effects From Mediated Semantic-Phonological Distractors}

There was a trend toward faster responses in the mediated condition than in the unrelated condition, but this trend was not reliable in the item analysis, $F_{1}(1,47)=6.71, M S E=354.52 ; F_{2}(1,15)=1.29$, $p=.27, M S E=701.11$, for naming latencies, and $F_{1}$ and $F_{2}<1$, for error rates. Naming latencies and error rates increased at an SOA of $-300 \mathrm{~ms}, F_{1}(2,94)=17.20, M S E=1,319.83 ; F_{2}(2,30)=37.82$, $M S E=212.07$, for naming latencies, and $F_{1}(2,94)=8.12, M S E=$ $0.43 ; F_{2}(2,30)=3.19, p=.06, M S E=3.30$, for error rates. There was no interaction of relatedness and $\operatorname{SOA}\left(F_{1}\right.$ and $F_{2}<1$, for naming latencies and error rates). 
Table 3

Mean Naming Latencies (in Milliseconds) and Errors (in Percentages) From Experiment 3

\begin{tabular}{|c|c|c|c|c|c|c|}
\hline \multirow{2}{*}{$\begin{array}{c}\text { Distractor } \\
\text { type }\end{array}$} & \multicolumn{3}{|c|}{ Phonological conditions } & \multicolumn{3}{|c|}{ Mediated semantic-phonological conditions } \\
\hline & SOA $-600 \mathrm{~ms}$ & $\mathrm{SOA}-450 \mathrm{~ms}$ & $\mathrm{SOA}-300 \mathrm{~ms}$ & $\mathrm{SOA}-600 \mathrm{~ms}$ & $\mathrm{SOA}-450 \mathrm{~ms}$ & $\mathrm{SOA}-300 \mathrm{~ms}$ \\
\hline \multicolumn{7}{|l|}{ Related } \\
\hline$M$ & 592 & 602 & 618 & 589 & 599 & 618 \\
\hline$S E$ & 9 & 9 & 10 & 8 & 9 & 10 \\
\hline$\%$ error & 1.4 & 2.2 & 3.0 & 1.4 & 1.7 & 3.5 \\
\hline$S E$ & 0.5 & 0.6 & 0.5 & 0.6 & 0.4 & 0.7 \\
\hline \multicolumn{7}{|l|}{ Unrelated } \\
\hline$M$ & 595 & 607 & 624 & 596 & 602 & 626 \\
\hline$S E$ & 8 & 9 & 9 & 8 & 10 & 10 \\
\hline$\%$ error & 1.3 & 1.7 & 2.3 & 1.6 & 2.0 & 3.9 \\
\hline$S E$ & 0.5 & 0.5 & 0.7 & 0.6 & 0.5 & 0.7 \\
\hline \multicolumn{7}{|l|}{ Difference } \\
\hline$M$ & -3 & -6 & -6 & $-7 * / n s$ & -3 & $-8^{* / n s}$ \\
\hline$S E$ & 5 & 5 & 5 & 3 & 4 & 4 \\
\hline$\%$ error & 0.1 & 0.5 & 0.7 & -.1 & -0.3 & -0.4 \\
\hline$S E$ & 0.4 & 0.7 & 0.8 & 0.6 & 0.6 & 0.9 \\
\hline
\end{tabular}

Note. Positive difference scores reflect interference, and negative difference scores reflect facilitation. Significance of these scores is indicated by the superscripts. The first superscript indicates results from the $t$ tests by participant. The second superscript indicates results from the $t$ tests by item. SOA $=$ stimulus onset asynchrony.

$* p<.05$

The first thing to note is that the SOA shift used in this experiment was appropriate for equating distractor processing time prior to response initiation in second graders and adults. Whereas the lag between distractor onset and speech onset had amounted to $1,184 \mathrm{~ms}$ and $784 \mathrm{~ms}$ at SOAs of $150 \mathrm{~ms}$ and $300 \mathrm{~ms}$, respectively, for children in Experiment 1A, it amounted to 1,196 ms, 1,055 ms, and $925 \mathrm{~ms}$ at SOAs of $-600 \mathrm{~ms},-450 \mathrm{~ms}$, and $-300 \mathrm{~ms}$, respectively, for adults in the present experiment (values based on averaged naming latencies for the two unrelated control conditions). Of importance, no evidence for interference from mediated semantic-phonological distractors was obtained with adult participants after this SOA shift. If anything, there was a slight trend in the opposite direction. Hence, the outcome of Experiment 3 confirms that the differential pattern obtained for children and adults in Experiment 1 cannot be attributed to longer distractor-response lags in children as compared with adults.

\section{General Discussion}

Using the picture-word interference task, Experiment 1 tested for facilitation from phonologically related distractors, indexing phonological activation of the target word, and interference from mediated semantic-phonological distractors, indexing possible phonological coactivation of semantic category coordinates, in speakers of different ages (second graders, fourth graders, and adults). We observed two clear developmental trends.

First, naming latencies and error rates decreased substantially with age. This pattern replicates earlier observations (e.g., Berman et al., 1989; Clark \& Johnson, 1994; Denckla \& Rudel, 1974; Guilford \& Nawojczyk, 1988). Most likely, it reflects improvements in both perceptual-conceptual and lexical processing, but the extant studies do not provide a unanimous answer to the question of which particular subprocesses contribute most to the observed effect.

Second, distractor effects were largest in the youngest participants and decreased with age. Again, a similar pattern has been reported previously in unimodal versions of the picture-word task for semantic distractors (e.g., Ehri, 1976; Rosinski, 1977; Rosinski, Golinkoff, \& Kukish, 1975): This pattern can be related to the gradual maturation of inhibitory mechanisms; with increasing age, children become more proficient in suppressing distracting stimuli (e.g., Bjorklund \& Hanishfeger, 1990; Dempster, 1992; Tipper, Bourque, Anderson, \& Brehaut, 1989). Most important, the age related change was observed not only for facilitation for phonologically related distractors, reflecting the activation of the target word's phonological representation, but also for interference from mediated distractors, reflecting the activation of a semantic category coordinate's phonological representation. Although no such interference was visible in adults, there was a corresponding trend in fourth graders and a sizable effect in second graders.

Experiment 2 ruled out that the differential pattern from Experiment 1 was due to comprehension processes (i.e., distractor recognition) rather than production processes (i.e., object name retrieval). In an auditory word-picture matching task, children and adults yielded identical response patterns: no specific effect if there was a mediated relation between word and picture but strong interference if there was a semantic relation between word and picture. In particular, this pattern rules out the possibility that young children are less efficient in deactivating inappropriate candidates from the set of lemma representations initially activated by an auditory distractor word. Hence, this pattern also suggests that the locus of the effect must be the phonological level, not the lemma level. Otherwise, similar patterns should have been observed in the semantic and the mediated condition of this experiment.

Experiment 3, finally, ruled out that the difference in the time available for distractor processing until response onset rather than the speed of lexical retrieval is the source of the differential pattern. When SOAs for adult participants were shifted such that the span between distractor onset and speech onset was comparable to the span children had exhibited in Experiment 1, no specific 
effects from mediated distractors was found. Hence, the outcome of Experiment 3 shows that the differential pattern obtained for children and adults in Experiment 1 cannot be attributed to the time available for distractor processing prior to response initiation, during which activation triggered by the distractor might have reverberated in the mental lexicon, possibly affecting the state of representations subsequently accessed during speech planning.

How does this difference in performance patterns for young and adult speakers relate to the discussion on serial-discrete versus nondiscrete (i.e., forward-cascaded or interactive) models of lexical retrieval? The most obvious interpretation is that the developmental perspective stretches out the lexical retrieval processes in time to such a great extent that a by hypothesis small mediated effect (Dell \& O'Seaghdha, 1991, 1992; Harley, 1993; O’Seaghdha \& Marin, 1997) indicative of cascaded processing can reliably be detected. Support for this hypothesis might be derived from the fact that there was a very small and nonreliable 3-ms difference in the expected direction for adults (SOAs of 0 and $150 \mathrm{~ms}$, with overall latencies of $559 \mathrm{~ms}$ ), and a reliable 57-ms difference for second graders (collapsed over SOAs of 150 and $300 \mathrm{~ms}$, with overall latencies of $1,214 \mathrm{~ms}$ ) in our study. Similar trends, though nonsignificant, were visible in some previous studies. For example, there was a reaction time difference of $12 \mathrm{~ms}$ in the expected direction with a corresponding $7 \%$ difference in the number of missing observations between the mediated and the unrelated conditions (which include errors) in Experiment 5 reported by Levelt et al. (1991), testing adult speakers. However, there was no such trend in a study by Jescheniak et al. (2003), using an event-related potential approach, and no effect in an unpublished study conducted by one of the reviewers of this article. However, studies focusing on situations in which either the semantic similarity or the phonological similarity component of the mediated pathway was in some way enhanced did obtain reliable mediated priming effects. As just mentioned, the word goal (related to goat) has little if any influence on the retrieval of sheep in adult speakers. However, enhancing the semantic similarity (e.g., count priming sofa via couch) does lead to mediated priming (Jescheniak \& Schriefers, 1998; Peterson \& Savoy, 1998). Also, enhancing phonological similarity (e.g., dance priming a round ball, via the identical phonological relation of homophony) leads to mediated priming (Cutting \& Ferreira, 1999).

These results suggest that mediated priming does occur (and hence that cascading is true), but that the effects are generally hard to detect. This was the argument given by Dell and O'Seaghdha (1991, 1992) when interpreting the absence of significant mediated priming in the study by Levelt et al. (1991) — a mediated effect is necessarily much smaller than either of the direct effects that make it up. If, however, the lexical retrieval process is stretched out in time (as was the case for young children tested in the present study), the direct phonological effects (and presumably also the direct semantic effects) are so large that one can now also observe the mediated effects for category coordinates. Thus, just as these other studies promoted the detection of mediated effects by making the pathways stronger, the present study did the same by slowing things down.

This view, of course, does not rule out the possibility that some gradual change of the lexical retrieval procedure occurs in the course of development. One could speculate whether the interaction of relatedness and age observed for the mediated condition reflects more than a mere proportional magnification of a small-sized trend present in the adult data. Possibly, it also indicates that lexical retrieval in young speakers differs from that in adult speakers in that cascading is less constrained in children than in adult speakers. This notion of processing differences between populations of speakers relates to an argument advanced by Dell et al. (1997). These authors compared picture-naming errors in speakers with aphasia, in which lexical retrieval is likewise impaired, and healthy controls and demonstrated that quantitative alterations to an interactive model parameterized to fit the normal error pattern were sufficient to explain much of the variability in patient error patterns. It appears likely that similar parameter alterations could also account for the developmental trend observed in the present study. One could thus speculate that-as lexical retrieval gets more efficient in the course of development-a more constrained type of processing emerges, correlated with optimized parameter settings. Under this perspective, increased language experience and efficiency would lead not only to faster but also to more fine-tuned lexical activation and retrieval.

Whether or not such gradual changes do occur cannot be ultimately decided based on the present data. Still, our study adds significantly to the theoretical discussion on discrete-serial versus forward-cascading and interactive models of lexical retrieval in that it shows that phonological coactivation of lexical competitors, indicative of forward-cascaded processing, is limited neither to name alternatives such as near synonyms or hierarchically related terms (as suggested by Levelt et al., 1999) nor to situations in which failures of lexical retrieval lead to overt error. This is an important result because alternative accounts of extant data promoting the cascading view have been provided in the past. On the one hand, it has been suggested that the ultimate test of a processing model of normal speech production should best come from chronometric analyses of error-free speech (Levelt et al., 1991). On the other hand, the effects obtained for near synonyms have been considered to reflect an exceptional case, namely, the erroneous selection of contextually appropriate name alternatives in addition to the target, leading to the simultaneous activation of multiple phonological forms, which is compatible with some form of a discrete-serial model (Levelt et al., 1999; but see Jescheniak et al., 2005). However, to our knowledge, the theoretical significance of the case under investigation here (i.e., presence vs. absence of phonological coactivation of semantic category coordinates) has not been questioned thus far. In fact, proponents of different models have taken the failure to detect such an effect in the past either as reason for refuting nondiscrete models (Levelt et al., 1991, 1999) or for parameterizing such models accordingly (Dell \& O'Seaghdha, 1991, 1992; Harley, 1993). Thus, our finding of such an effect in young speakers contributes one important piece of evidence to the emerging picture of lexical retrieval in speaking as a-constrained-forward-cascaded process, according to which phonological activation is not contingent on lexical selection. Last but not least, our study shows that chronometric analyses of lexical retrieval processes are also feasible with young speakers; in fact, such studies may shed new light on highly controversial issues in the domain of adult lexical processing. A natural and promising extension of this work would be to address normal variation among healthy adults as well as contrasts with young and impaired populations in future research. For example, do slower or less linguistically proficient speakers show the same tendencies as the young speakers tested here? On the view advanced here they should, and if this prediction is borne out by new data, the cascaded processing view would gain even more support. 


\section{References}

Berman, S., Friedman, D., Hamberger, M., \& Snodgrass, J. G. (1989). Developmental picture norms: Relationships between name agreement, familiarity, and visual complexity for child and adult ratings of two sets of line drawings. Behavior Research Methods, Instruments, \& Computers, 21, 371-382.

Bjorklund, D. F., \& Hanishfeger, K. K. (1990). The resources construct in cognitive development: Diverse sources of evidence and a theory of insufficient inhibition. Developmental Review, 10, 48-71.

Caramazza, A. (1997). How many levels of processing are there in lexical access? Cognitive Neuropsychology, 14, 177-208.

Clark, J. M., \& Johnson, C. L. (1994). Retrieval mechanisms in the development of instance and superordinate naming of pictures. Journal of Experimental Child Psychology, 57, 295-326.

Cutting, C. J., \& Ferreira, V. S. (1999). Semantic and phonological information flow in the production lexicon. Journal of Experimental Psychology: Learning, Memory, and Cognition, 25, 318-344.

Damian, M. F., \& Martin, R. C. (1999). Semantic and phonological codes interact in single word production. Journal of Experimental Psychology: Learning, Memory, and Cognition, 25, 345-361.

Dell, G. S. (1986). A spreading-activation theory of retrieval in sentence production. Psychological Review, 93, 283-321.

Dell, G. S., \& O'Seaghdha, P. G. (1991). Mediated and convergent lexical priming in language production: A comment on Levelt et al. (1991). Psychological Review, 98, 604-614.

Dell, G. S., \& O'Seaghdha, P. G. (1992). Stages of lexical access in language production. Cognition, 42, 287-314

Dell, G. S., \& Reich, P. (1981). Stages in sentence production: An analysis of speech error data. Journal of Verbal Learning and Verbal Behavior, 20, 611-629.

Dell, G. S., Schwartz, M. F., Martin, N., Saffran, E. M., \& Gagnon, D. A. (1997). Lexical access in aphasic and nonaphasic speakers. Psychological Review, 104, 801-838.

Dempster, F. N. (1992). The rise and fall of the inhibitory mechanism: Toward a unified theory of cognitive development and aging. Developmental Review, 12, 45-75.

Denckla, M. B., \& Rudel, R. G. (1974). Rapid "automatized" naming of pictured objects, colors, letters, and numbers by normal children. Cortex, $10,186-202$

Ehri, L. C. (1976). Do words really interfere in naming pictures? Child Development, 47, 502-505.

Ferreira, V. S., \& Griffin, Z. M. (2003). Phonological influences on lexical (mis)selection. Psychological Science, 14, 86-90.

Fowler, A. E. (1991). How early phonological development might set the stage for phonological awareness. In S. A. Brady \& D. P. Shankweiler (Eds.), Phonological processes in literacy: A tribute to Isabelle Y. Liberman (pp. 97-117). Hillsdale, NJ: Erlbaum.

Garlock, V. M., Walley, A. C., \& Metsala, J. L. (2001). Age-of-acquisition, word frequency, and neighborhood density effects on spoken word recognition by children and adults. Journal of Memory and Language, 45, 468-492.

Garrett, M. F. (1988). Processes in language production. In F. J. Newmeyer (Ed.), Linguistics: The Cambridge survey: Vol. 3. Language: Psychological and biological aspects (pp. 69-96). Cambridge, MA: Harvard University Press.

Garrett, M. F. (1992). Disorders of lexical selection. Cognition, 42, 143-180.

Glaser, W. R., \& Düngelhoff, F. J. (1984). The time course of picture-word interference. Journal of Experimental Psychology: Human Perception and Performance, 10, 640-654.

Guilford, A. M., \& Nawojczyk, D. C. (1988). Standardization of the Boston Naming Test at the kindergarten and elementary school levels. Language, Speech, and Hearing Services in Schools, 19, 395-399.

Harley, T. A. (1993). Phonological activation of semantic competitors during lexical access in speech production. Language and Cognitive Processes, 8, 291-309.
Jerger, S., Martin, R. C., \& Damian, M. F. (2002). Semantic and phonological influences on picture naming by children and teenagers. Journal of Memory and Language, 47, 229-249.

Jescheniak, J. D., Hahne, A., \& Schriefers, H. (2003). Information flow in the mental lexicon: Evidence from event-related brain potentials. Cognitive Brain Research, 15, 261-276.

Jescheniak, J. D., Hantsch, A., \& Schriefers, H. (2005). Context effects on lexical choice and activation. Journal of Experimental Psychology: Learning, Memory, and Cognition, 31, 905-920.

Jescheniak, J. D., \& Schriefers, H. (1998). Discrete serial versus cascaded processing in lexical access in speech production: Further evidence from the coactivation of near-synonyms. Journal of Experimental Psychology: Learning, Memory, and Cognition, 24, 1256-1274.

Jescheniak, J. D., Schriefers, H., \& Hantsch, A. (2001). Semantic and phonological activation in noun and pronoun production. Journal of Experimental Psychology: Learning, Memory, and Cognition, 27, 1058-1078.

Johnson, C. J. (1992). Cognitive components of naming in children: Effects of referential uncertainty and stimulus realism. Journal of Experimental Child Psychology, 53, 24-44.

Johnson, C. J., Paivio, A., \& Clark, J. M. (1996). Cognitive components of picture naming. Psychological Bulletin, 120, 113-139.

Jusczyk, P. W. (1986). Toward a model of the development of speech perception. In J. S. Perkell \& H. D. Klatt (Eds.), Invariance and variability in speech processes (pp. 1-19). Hillsdale, NJ: Erlbaum.

Jusczyk, P. W. (1992). Developing phonological categories from the speech signal. In C. A. Ferguson, L. Menn, \& C. Stoel-Gammon (Eds.), Phonological development: Models, research, implications (pp. 17-64). Parkton, MD: York Press.

Levelt, W. J. M. (1992). Accessing words in speech production: Stages, processes, and representations. Cognition, 42, 1-22.

Levelt, W. J. M., Roelofs, A., \& Meyer, A. S. (1999). A theory of lexical access in speech production. Behavioral and Brain Sciences, 22, 1-75.

Levelt, W. J. M., Schriefers, H., Vorberg, D., Meyer, A. S., Pechmann, T., \& Havinga, J. (1991). The time course of lexical access in speech production: A study of picture naming. Psychological Review, 98, 122-142.

Lupker, S. J. (1979). The semantic nature of response competition in the picture-word interference task. Memory \& Cognition, 7, 485-495.

Marslen-Wilson, W. D. (1987). Functional parallelism in spoken word recognition. Cognition, 25, 71-102.

Martin, N., Gagnon, D. A., Schwartz, M. F., Dell, G. S., \& Saffran, E. M. (1996). Phonological facilitation of semantic errors in normal and aphasic speakers. Language and Cognitive Processes, 11, 257-282.

Martin, N., Weisberg, R. W., \& Saffran, E. M. (1989). Variables influencing the occurrence of naming errors: Implications for a model of lexical retrieval. Journal of Memory and Language, 28, 462-485.

Morsella, E., \& Miozzo, M. (2002). Evidence for a cascade model of lexical access in speech production. Journal of Experimental Psychology: Learning, Memory, and Cognition, 28, 555-563.

O'Seaghdha, P. G., \& Marin, J. W. (1997). Mediated semanticphonological priming: Calling distant relatives. Journal of Memory and Language, 36, 226-252.

Peterson, R. R., \& Savoy, P. (1998). Lexical selection and phonological encoding during language production: Evidence for cascaded processing. Journal of Experimental Psychology: Learning, Memory, and Cognition, 24, 539-557.

Rosinski, R. R. (1977). Picture-word interference is semantically based. Child Development, 48, 643-647.

Rosinski, R., Golinkoff, R., \& Kukish, K. (1975). Automatic semantic processing in a picture-word interference task. Child Development, 46, 247-253.

Schriefers, H., Meyer, A. S., \& Levelt, W. J. M. (1990). Exploring the time course of lexical access in production: Picture-word interference studies. Journal of Memory and Language, 29, 86-102.

Starreveld, P. (2000). On the interpretation of phonological context effects in word production. Journal of Memory and Language, 42, 497-525. 
Starreveld, P., \& La Heij, W. (1995). Semantic interference, orthographic facilitation, and their interaction in naming tasks. Journal of Experimental Psychology: Learning, Memory, and Cognition, 21, 686-698.

Tipper, S. P., Bourque, T. A., Anderson, S. H., \& Brehaut, J. C. (1989). Mechanisms of attention: A developmental study. Journal of Experimental Child Psychology, 48, 353-378.

Underwood, G. (1976). Semantic interference from unattended printed words. British Journal of Psychology, 67, 327-338.

Vigliocco, G., Vinson, D. P., Martin, R. C., \& Garrett, M. F. (1999). Is "count" and "mass" information available when the noun is not? An investigation of tip of the tongue states and anomia. Journal of Memory and Language, 40, 534-558.

Walley, A. C. (1988). Spoken word recognition by young children and adults. Cognitive Development, 3, 137-165.

Walley, A. C. (1993). The role of vocabulary growth in children's spoken word recognition and segmentation ability. Developmental Review, 13, 286-350.

Walley, A. C., Michela, V. L., \& Wood, D. R. (1995). The gating paradigm: Effects of presentation format on spoken word recognition by children and adults. Perception \& Psychophysics, 57, 343-351.

Zwitserlood, P. (1989). The locus of the effects of sentential-semantic context in spoken-word processing. Cognition, 32, 25-64.

\section{Appendix A}

Object Names and Distractor Words Used in Experiments 1 and 3

\begin{tabular}{|c|c|c|c|}
\hline \multirow[b]{2}{*}{ Object name } & \multirow[b]{2}{*}{$\begin{array}{l}\text { Mediating semantic } \\
\text { category coordinate }\end{array}$} & \multicolumn{2}{|c|}{ Distractor } \\
\hline & & Phonological & $\begin{array}{l}\text { Mediated semantic- } \\
\text { phonological }\end{array}$ \\
\hline Bett [bed] & Sofa $[$ sofa] & Berg [mountain] & Sosse [sauce] \\
\hline Bus [bus] & Laster $[$ truck] & Busch [bush] & Lasso [lasso] \\
\hline Gans [goose] & Hahn [rooster] & Gast [guest] & Hafen [harbor] \\
\hline Kissen [pillow] & Decke [blanket] & Kiste [box] & Delle [buckle] \\
\hline Mantel [coat] & Hose [trousers] & Maske [mask] & Honig [honey] \\
\hline Maus [mouse] & Ratte [rat] & Mauer [wall] & Rassel [rattle] \\
\hline Mütze [cap] & Hut [hat] & Mücke [mosquito] & Huhn [hen] \\
\hline Nase [nose] & Mund [mouth] & Nadel [needle] & Muschel [shell] \\
\hline Schaf [sheep] & Ziege [goat] & Schal [scarf] & Ziel [goal] \\
\hline Schiff [ship] & Boot [boat] & Schild [sign] & Bohne [bean] \\
\hline Sessel [armchair] & Stuhl [chair] & Senf [mustard] & Stufe [stair] \\
\hline Sonne [sun] & Stern [star] & Socke [sock] & Stecker [plug] \\
\hline Tasse [cup] & Becher [cup] & Tatze [paw] & Becken [basin] \\
\hline Topf [pot] & Pfanne [pan] & Tochter [daughter] & Pfarrer [parson] \\
\hline Wurm [worm] & Käfer [beetle] & Wurst [sausage] & Käfig [cage] \\
\hline Zange [pliers] & Hammer [hammer] & Zapfen [cone] & Halle [hall] \\
\hline
\end{tabular}

Appendix B

Object Names and Words Used in the Semantic Conditions of Experiment 2

\begin{tabular}{|c|c|}
\hline Object name & Semantically related probe word \\
\hline Apfel [apple] & Birne [pear] \\
\hline Auto [car] & Moped [moped] \\
\hline Buch [book] & Zeitung [newspaper] \\
\hline Brot [bread] & Torte [cake] \\
\hline Eis [ice cream] & Lutscher [lollipop] \\
\hline Fuchs [fox] & $\operatorname{Reh}[\mathrm{deer}]$ \\
\hline Kleid [dress] & Rock [skirt] \\
\hline Koffer [suitcase] & Ranzen [knapsack] \\
\hline Kran [crane] & Bagger [dredger] \\
\hline Löwe [lion] & Tiger [tiger] \\
\hline Lupe [magnifying glass] & Brille [glasses] \\
\hline Pinsel [brush] & Stift $[$ pen] \\
\hline Puppe [doll] & Teddy [teddy bear] \\
\hline Roller [scooter] & Schlitten [sledge] \\
\hline Seil [rope] & Faden [thread] \\
\hline Trommel [drum] & Klavier [piano] \\
\hline
\end{tabular}

Note. Object names and probe words used in the mediated conditions correspond to the object names and distractor words listed in Appendix A. 